\title{
Changes in skeletal muscle microcirculation after a hemodialysis session correlates with adequacy of dialysis
}

This article was published in the following Dove Press journal: International Journal of Nephrology and Renovascular Disease 8 June 2015

Number of times this article has been viewed

\author{
Chrysoula Pipili' \\ Eirini Grapsa' \\ Elli-Sophia Tripodaki' \\ Sophia loannidou ${ }^{2}$ \\ Christos Manetos' \\ Maria Parisi' \\ Serafim Nanas' \\ 'First Critical Care Department, \\ ${ }^{2}$ Laboratory of Biochemistry, \\ Evangelismos General Hospital, \\ National and Kapodistrian University \\ of Athens, Athens, Greece
}

Background: Monitoring of the microcirculation may add additional information in terms of improving the adequacy of hemodialysis (HD) for patients. Withdrawal of liquid and complement activation during a HD session reduces the external pressure on the microcirculation and leads to an increased dilatation of the peripheral capillaries. The purposes of this study were to assess the effect of a single HD or hemodiafiltration session on the thenar microcirculation in patients with end-stage renal disease (ESRD) with or without diabetes, investigate the possible relationship between changes in the microcirculation and adequacy of dialysis (including $\mathrm{Kt} / \mathrm{V}$ and parameters indicating secondary hyperparathyroidism), and compare microcirculation measurements obtained from patients with ESRD and those from healthy controls.

Methods: This pilot prospective observational study including eleven patients with ESRD on maintenance HD (nine men of mean age $73 \pm 10.5$ years, ten [91\%] with hypertension), nine patients with ESRD on maintenance hemodiafiltration (six men of mean age 65.5 \pm 13.2 years, five [55.5\%] with diabetes and four [44.5\%] with hypertension), and eight healthy volunteers. Two paired microcirculation assessments were recorded for each HD patient before and after a dialysis session. Near infrared spectroscopy and the vascular occlusion test were used to assess the microcirculation, and blood work samples were collected before and after dialysis when the pump slowed down.

Results: Patients with ESRD showed an increase in thenar cell metabolism at rest after a 4-hour HD session, and changes in cell metabolism correlated with the $\mathrm{Kt} / \mathrm{V}$ of the session. Pre-dialysis tissue oxygen saturation over the 4-hour HD session correlated with pre-dialysis serum calcium and parathyroid hormones. Vascular reactivity was lower in ESRD patients receiving HD or hemodiafiltration than in healthy controls.

Conclusion: Improvement in skeletal muscle microcirculation noted after a HD session was related to adequacy of dialysis. Evaluation of the microcirculation may provide additional information for management of patients on HD and identify novel targets for treatment. These preliminary findings need to be tested using a larger data set.

Keywords: hemodiafiltration, near infrared spectroscopy, end stage renal disease, single-pool Kt/V

\section{Introduction}

Parameters related to adequacy of dialysis are numerous, and simply monitoring one of them is insufficient. Considering the impact of adequacy of dialysis on quality of life, rigorous attempts to achieve the desired goals are necessary. ${ }^{1,2}$ Awareness of how and the extent to which hemodialysis (HD) affects the microcirculation in skeletal muscle may be clinically important. Changes in the microcirculation have been recorded, particularly in patients suffering from diabetes mellitus, ${ }^{3,4}$ arterial hypertension, ${ }^{5}$ and peripheral arterial disease. ${ }^{6}$ In particular, near infrared spectroscopy
Correspondence: Chrysoula Pipili First Critical Care Department, Evangelismos General Hospital, National and Kapodistrian University of Athens, Ypsilantou 45-47, 10675, Athens, Greece Fax +30 21 32043385

Email chrysapi200I@gmail.com 
(NIRS) in combination with the vascular (arterial and venous) occlusion test (VOT) is a simple method for monitoring peripheral tissue oxygenation at the bedside, the tissue oxygen consumption rate at ischemia, and meaning and the functionality and integrity of the endothelium. ${ }^{6,7}$ NIRS has been used in various clinical situations, including in intensive care patients, ${ }^{6,8,9}$ patients with chronic heart failure, ${ }^{7,10}$ and healthy volunteers. ${ }^{1-13}$

The purpose of this study was to assess the effects of HD or hemodiafiltration (HDF) on the thenar microcirculation in patients with end-stage renal disease (ESRD) and with or without diabetes receiving maintenance HD (as estimated by NIRS and VOT), to investigate the possible relationship between changes in the microcirculation and adequacy of dialysis (including $\mathrm{Kt} / \mathrm{V}$ and parameters associated with secondary hyperparathyroidism), and to compare NIRS measurements obtained from ESRD patients with those in healthy controls. Monitoring of the microcirculation may add additional information in terms of improving the adequacy of HD for patients.

\section{Materials and methods Selection of subjects}

We conducted a prospective observational pilot study among ESRD patients undergoing regular dialysis sessions. Patients were excluded if they were younger than 18 years of age, had a high body mass index $\left(\geq 35 \mathrm{~kg} / \mathrm{m}^{2}\right)$, and had generalized edema. Demographic details and data on dialysis parameters were recorded for all patients. Healthy volunteers were screened by clinical history, physical examination, and routine chemical analysis. None showed present or past evidence of diabetes, hypercholesterolemia, chronic renal failure, peripheral artery disease, or cardiovascular disease. All patients enrolled in the study were asked to refrain from caffeine-containing drinks for at least 2 hours before the start of measurements. Informed consent was obtained from all study participants.

\section{Measurement protocol}

Two paired microcirculation assessments were recorded for each HD patient just prior to the start and at the end of one mid-week dialysis session. The pre-dialysis assessment started before insertion of arterial and venous lines in a sitting position. NIRS was used to measure thenar muscle oxygen saturation before, during, and after brachial artery occlusion on the hand contralateral to arteriovenous access placement. Each patient's pre-dialysis and post-dialysis blood pressure and weight were also noted. Routine blood samples were collected pre-dialysis and post-dialysis when the pump slowed down and before the lines were flushed with saline. Serum calcium, phosphorus, and parathyroid hormone were measured at the beginning of the HD session. The measurement of the second microcirculation was performed using VOT after removal of the HD lines and in the sitting position. Single-pool $\mathrm{Kt} / \mathrm{V}$ was calculated by using pre-dialysis and post-dialysis urea, duration often a single HD session and ultrafiltration removal over the same session.

Analysis of tissue oxygen saturation $\left(\mathrm{StO}_{2}\right)$ curves and estimation of the adequacy of dialysis were then performed using single-pool Kt/V. Percentage change in the parameters was estimated by subtraction of pre-dialysis (baseline) values from post-dialysis values divided with pre-dialysis values and multiplied by 100 . NIRS variables were measured in healthy seated volunteers.

\section{Near infrared spectroscopy and the vascular occlusion test}

NIRS is a promising, easily applicable, noninvasive system for monitoring of the microcirculation in skeletal muscle. It is based on the capacity of hemoglobin to absorb infrared light at different and well separated wavelengths (680-800 nm). By illuminating and collecting back-scattered light from tissue, NIRS methodology can determine the percentage of oxyhemoglobin in total hemoglobin (oxygenated or not oxygenated) for a certain tissue volume $\left(\mathrm{StO}_{2}\right) .{ }^{12}$ Infrared light can penetrate to a depth of $12.5 \mathrm{~cm}$, allowing accurate measurement of skeletal muscle $\mathrm{StO}_{2}$ while ignoring the superjacent skin and subcutaneous microcirculation. ${ }^{13}$

In the present study, thenar $\mathrm{StO}_{2}$ was measured noninvasively using a second-generation NIRS device (Inspectra Model 325, Hutchinson Technology, McLeod County, MN, USA). First, a sphygmomanometer cuff was placed around the patient's arm, and a transdermal light probe was placed on the patient's ipsilateral thenar area. Baseline arterial pressure and $\mathrm{StO}_{2}$ were then recorded after a 3-minute stabilization period. Next, ischemia was introduced by rapid inflation of the pneumatic cuff to $50 \mathrm{mmHg}$ above the patient's systolic blood pressure. Vascular occlusion (mostly of the brachial artery) was maintained for 3 minutes, during which the decrease in thenar $\mathrm{StO}_{2}$ was recorded (ischemia phase). The cuff was then rapidly deflated, noting an increase in thenar $\mathrm{StO}_{2}$ (reperfusion phase). Monitoring was continued until $\mathrm{StO}_{2}$ returned to its baseline value (hyperemia phase). ${ }^{12}$ The $\mathrm{StO}_{2}$ data were retrospectively analyzed using the software provided by the manufacturer (Inspectra Analysis Program version 4.01, Hutchinson Technology). Linear regression analysis was used to estimate the VOT-derived $\mathrm{StO}_{2}$ parameters, the rate of 
hemoglobin desaturation during ischemia (oxygen consumption rate, percent per minute), the $\mathrm{StO}_{2}$ growth curve during reperfusion, which represents microvascular and precapillary sphincter reactivity (endothelial function, percent per second), and the hyperemia phase (vascular reactivity). ${ }^{11}$

\section{Statistical analysis}

Measurements before and after the HD session were compared by paired $t$-test, and the $\chi^{2}$ or Fisher's Exact test was used to compare nominal variables. Descriptive characteristics and results from the three subject groups were compared by analysis of variance. Comparative analysis between the groups was performed by analysis of variance with a Bonferroni post hoc test. Correlation analysis was done by Pearson's analysis for normally distributed datasets. Differences between groups were considered to be statistically significant at $P<0.05$. All data are presented as the mean \pm standard deviation.

\section{Results}

Twenty-eight subjects were enrolled in the study. Eleven were ESRD patients who had been on maintenance HD for $4.5 \pm 3$ years (nine males and two females, mean age $73.0 \pm 10.5$ years, mean body mass index $27.0 \pm 0.3$, including ten [91\%] with hypertension and none with diabetes), nine were ESRD patients who had been on maintenance HDF for $4.0 \pm 2.5$ years (six males and three females, mean age $65.5 \pm 13.2$ years, body mass index $24.0 \pm 03.7$, including five $[55.5 \%]$ with diabetes, four [44.5\%] with hypertension, and two with coexisting hypertension and diabetes), and eight were healthy volunteers. Baseline demographic data and clinical characteristics for all patients and healthy subjects are presented in Table 1. All ESRD patients with hypertension were treated with nifedipine $5-15 \mathrm{mg} /$ day. Other antihypertensive medications were not administered. All dialyzers were made of polysulfone with a membrane surface area of $1.5 \pm 0.2 \mathrm{~m}^{2}$, with the dialysate flow rate and temperature stable at $500 \mathrm{~mL}$ per minute and $36^{\circ} \mathrm{C}$, respectively. Low molecular weight heparin was used for anticoagulation. HDF was of low volume at $30 \pm 5 \mathrm{~mL} / \mathrm{kg} /$ hour. The characteristics of the ESRD patients receiving HD or HDF are summarized in Tables 2 and 3. Kt/V was not calculated in eight of the eleven patients on HD due to three missing sets of post-dialysis urea values.

Patients on HD showed an increased oxygen consumption rate after their 4-hour HD session (coefficient of variation $8.8 \%$, Table 2 ) and the percent change in oxygen consumption rate were positively correlated with the single-pool $\mathrm{Kt} / \mathrm{V}$
Table I Near infrared spectroscopy variables in patients with ESRD and in healthy volunteers

\begin{tabular}{|c|c|c|c|}
\hline & $\begin{array}{l}\text { ESRD } \\
(n=20)\end{array}$ & $\begin{array}{l}\text { Healthy } \\
\text { volunteers } \\
(n=8)\end{array}$ & $P$-value \\
\hline Age, years (mean $\pm S D$ ) & $69.5 \pm 12.0$ & $28.0 \pm 4.0$ & $<0.0001$ \\
\hline $\operatorname{Sex}(M / F)$ & $15 / 5$ & $8 / 0$ & 0.221 \\
\hline $\mathrm{BMI}, \mathrm{kg} / \mathrm{m}^{2}($ mean $\pm \mathrm{SD})$ & $26.0 \pm 3.4$ & $28.0 \pm 4.0$ & 0.192 \\
\hline Diabetes & $5(25 \%)$ & 0 & 0.65 \\
\hline Hypertension & $14(70 \%)$ & 0 & $<0.000$ I \\
\hline $\begin{array}{l}\text { Tissue oxygen saturation, \% } \\
\text { (mean } \pm \text { SD) }\end{array}$ & $79.6 \pm 14.3$ & $80.3 \pm 6.0$ & 0.32 \\
\hline $\begin{array}{l}\text { Oxygen consumption } \\
\text { rate, } \% / \min (\text { mean } \pm S D)\end{array}$ & $-31.4 \pm 19.2$ & $-37.7 \pm 5.5$ & 0.53 \\
\hline $\begin{array}{l}\text { Endothelial function, \%/min } \\
(\text { mean } \pm S D)\end{array}$ & $9.1 \pm 5.6^{*}$ & $15.7 \pm 6.3^{*}$ & 0.003 \\
\hline
\end{tabular}

Notes: One-way analysis of variance and Bonferroni post hoc test were used to test for statistically significant differences among groups. The statistical difference was set at $P<0.05$. $* P=0.005$ between ESRD and healthy volunteers.

Abbreviations: BMI, body mass index; ESRD, end-stage renal disease; $M$, male; F, female; SD, standard deviation.

( $R=0.74, P=0.03$, Figure 1). Further, in this patient group, the pre-dialysis $\mathrm{StO}_{2}$ was positively correlated with pre-dialysis serum parathyroid hormone $(R=0.70, P=0.02)$ and calcium ( $R=0.90, P<0.0001$, Figures 2 and 3). NIRS variables did not differ before and after a 4-hour HDF session (Table 3). Statistically significant differences in the pre-dialysis microcirculation were noted between patients with ESRD and healthy controls. Pre-dialysis endothelial function was lower in patients with ESRD (coefficient of variation 9.3\%, Table 1).

Table 2 Hemodynamic and biochemical characteristics of HD session $(n=I I)$

\begin{tabular}{|c|c|c|c|}
\hline & $\begin{array}{l}\text { Before start } \\
\text { of HD session }\end{array}$ & $\begin{array}{l}\text { After end } \\
\text { of HD session }\end{array}$ & $P$-value \\
\hline Systolic arterial & $125.5 \pm 13.7$ & $120.8 \pm 10.3$ & 0.264 \\
\hline \multicolumn{4}{|l|}{$\mathrm{BP}(\mathrm{mmHg})$} \\
\hline Weight (kg) & $77.8 \pm 8.1$ & $76.1 \pm 7.8$ & $<\mathbf{0 . 0 0 0 1}$ \\
\hline Hematocrit (\%) & $37.2 \pm 3.6$ & $39.2 \pm 6.9$ & 0.150 \\
\hline Urea (mg/dL) & $192.6 \pm 50.4$ & $76.7 \pm 37.8$ & $<0.0001$ \\
\hline Creatinine (mg/dL) & $9.7 \pm 2.5$ & $4.4 \pm 1.5$ & $<0.0001$ \\
\hline Calcium (mg/dL) & $8.8 \pm 1.7$ & $\mathrm{~N} / \mathrm{A}$ & \\
\hline Phosphorus (mg/dL) & $5.6 \pm 2.0$ & $\mathrm{~N} / \mathrm{A}$ & \\
\hline $\begin{array}{l}\text { Parathyroid hormone } \\
(\mathrm{pg} / \mathrm{mL})\end{array}$ & $483.0 \pm 297.5$ & N/A & \\
\hline $\mathrm{Kt} / \mathrm{V}$ per session & $1.1 \pm 0.3$ & & \\
\hline $\begin{array}{l}\text { Tissue oxygen } \\
\text { saturation (\%) }\end{array}$ & $81.8 \pm 11.9$ & $74.4 \pm 4.5$ & 0.113 \\
\hline $\begin{array}{l}\text { Oxygen consumption } \\
\text { rate }(\% / \mathrm{min})\end{array}$ & $24.5 \pm 7.5$ & $40 \pm 17.7$ & 0.030 \\
\hline $\begin{array}{l}\text { Endothelial function } \\
(\% / \mathrm{min})\end{array}$ & $9.9 \pm 5.5$ & $1 \mathrm{I} .4 \pm 6.5$ & 0.062 \\
\hline
\end{tabular}

Notes: Bold represent statistically significant figures. Values are presented as mean \pm standard deviation.

Abbreviations: BP, blood pressure; HD, hemodialysis; N/A, not applicable. 
Table 3 Hemodynamic and biochemical characteristics of hemodiafiltration session $(n=9)$

\begin{tabular}{|c|c|c|c|}
\hline & $\begin{array}{l}\text { Before start } \\
\text { of HD session }\end{array}$ & $\begin{array}{l}\text { After end of } \\
\text { HD session }\end{array}$ & $P$-value \\
\hline $\begin{array}{l}\text { Systolic arterial } \\
\text { BP }(\mathrm{mmHg})\end{array}$ & $136.6 \pm 25.9$ & $111.2 \pm 17.2$ & 0.046 \\
\hline Weight (kg) & $77.8 \pm 16.9$ & $76 \pm 12.5$ & $<\mathbf{0 . 0 0 0 I}$ \\
\hline Hematocrit (\%) & $39.4 \pm 2.6$ & $4 I \pm 4$ & 0.203 \\
\hline Urea (mg/dL) & $|44| \pm 35.3$. & $47.6 \pm 19.8$ & $<\mathbf{0 . 0 0 0 I}$ \\
\hline Creatinine (mg/dL) & $7.7 \pm 2.5$ & $2.9 \pm 1.3$ & $<\mathbf{0 . 0 0 0 I}$ \\
\hline Calcium (mg/dL) & $9.4 \pm 1.3$ & $\mathrm{~N} / \mathrm{A}$ & \\
\hline Phosphorus (mg/dL) & $5.6 \pm 2$ & $N / A$ & \\
\hline $\begin{array}{l}\text { Parathyroid hormone } \\
(\mathrm{pg} / \mathrm{mL})\end{array}$ & $483.1 \pm 297.5$ & $\mathrm{~N} / \mathrm{A}$ & \\
\hline $\begin{array}{l}\text { Tissue oxygen } \\
\text { saturation (\%) }\end{array}$ & $77.9 \pm 16.9$ & $76 \pm 12.5$ & 0.765 \\
\hline $\begin{array}{l}\text { Oxygen consumption } \\
\text { rate }(\% / \mathrm{min})\end{array}$ & $39.6 \pm 20.9$ & $53.4 \pm 33.8$ & 0.276 \\
\hline $\begin{array}{l}\text { Reperfusion rate } \\
(\% / \mathrm{min})\end{array}$ & $9.1 \pm 5.7$ & $7.1 \pm 3.8$ & 0.543 \\
\hline
\end{tabular}

Notes: Bold represent statistically significant figures. Values are presented as mean \pm standard deviation.

Abbreviations: BP, blood pressure; HD, hemodialysis; N/A, not applicable.

\section{Discussion}

The finding of this study that extends our current knowledge is the correlation between the improvement in cell metabolism conferred by a single HD session and adequacy of dialysis as indicated by the single-pool Kt/V. A possible explanation for this relationship is that HD rapidly clears uremic toxins as well as markers of endothelial damage (circulating endothelial microparticles), ${ }^{5}$ given that patients with ESRD have high levels of both. ${ }^{14}$ This result confirms our original hypothesis based on the work of Kong and Farrington, ${ }^{15}$ who suggested that

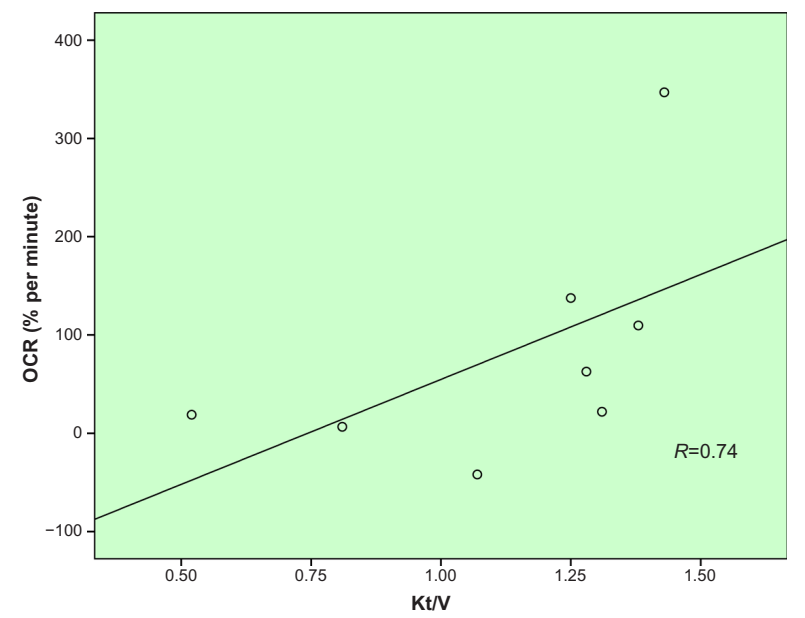

Figure I Correlation between increased OCR, ie, thenar cell metabolism at rest during a single mid-week hemodialysis session, and $\mathrm{Kt} / \mathrm{V}$ as a marker of the adequacy of hemodialysis $(R=0.74, P=0.03)$.

Abbreviation: OCR, oxygen consumption rate.

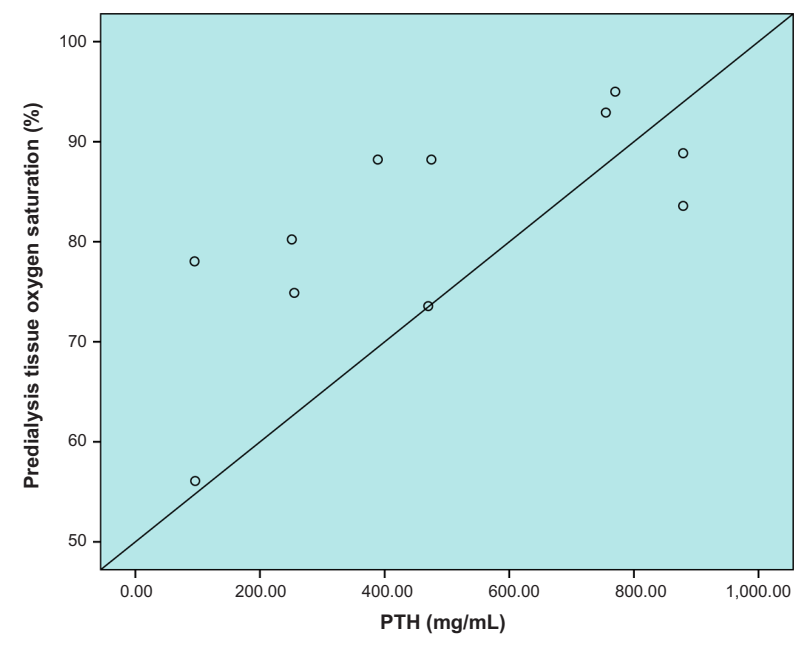

Figure 2 Changes in thenar tissue oxygen saturation over a single hemodialysis session correlate positively with PTH levels in patients undergoing hemodialysis $(R=0.70, P=0.02)$.

Abbreviation: PTH, parathyroid hormone.

clearance of substances during HD occurs not only at the level of the dialyzer but also at the level of the capillary membrane. Bearing in mind that nutrition, acidosis, and ultrafiltration rate are additional markers of the adequacy of dialysis, our results are consistent with those of previous studies showing that cutaneous blood flow is associated with albumin levels in patients on $\mathrm{HD}^{16}$ and that changes in the sublingual microcirculation are related to changes in volume during the HD procedure. ${ }^{17}$ Further, Kemp et $\mathrm{al}^{18}$ showed that the urea reduction ratio was negatively correlated with body mass index, reflecting the effect of muscle mass on the efficiency of dialysis.

The increased cell metabolism seen at the end of a HD session could be caused by the acute withdrawal of liquid

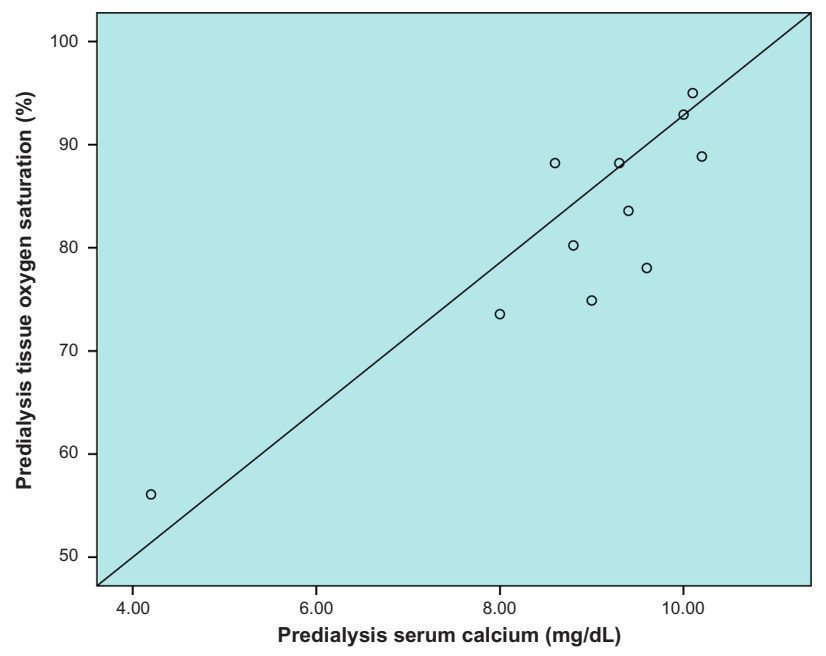

Figure 3 Changes in thenar tissue oxygen saturation over a single hemodialysis procedure correlate positively with pre-dialysis serum calcium levels in patients undergoing hemodialysis $(R=0.90, P<0.000 \mathrm{I})$. 
taking place during $\mathrm{HD}$, which reduces interstitial edema and the external pressure on the microcirculation, also triggering an increased dilatation of the peripheral capillaries. ${ }^{19}$ Vascular dilatation can be further provoked by complement activation and endothelial production of cytokines and prostacyclins, which occurs during $\mathrm{HD},{ }^{17,20}$ as well as by administration of vasodilating antihypertensives, ${ }^{4}$ which were common in our patient sample $(70 \%$ of the ESRD patients were on calcium antagonist therapy). The improvement in thenar cell metabolism may also be related to the increase in oxygenated hemoglobin levels at the end of the HD session. The affinity of hemoglobin for oxygen can be affected indirectly by extracellular agents, such as phosphorus and plasma $\mathrm{pH}$. It has been documented that the ability of hemoglobin to bind to oxygen is limited under conditions of acidosis and hyperphosphatemia, which are present in the pre-dialysis period, but improves after HD because of a reduction in phosphorus levels and an increase in $\mathrm{pH} .{ }^{21}$ Interestingly, improvement in the microcirculation was not observed in patients on maintenance hemodiafiltration. The heterogeneity of patients in this group, ie, presence of diabetes with or without hypertension, might have affected our findings. The influence of heparin in the microcirculation cannot be evaluated since it was administered to all patients.

In the literature, the majority of studies that have investigated the impact of HD on the smallest vessels have referred to microcirculation in the skin. ${ }^{17,22-24}$ Most of these data indicate that the microcirculation in the skin deteriorates during the HD procedure ${ }^{17,22-24}$ and patients with diabetes and peripheral arterial occlusive disease are more susceptible to impairments in the peripheral microcirculation and are at high risk of gangrene. ${ }^{23-25}$ Changes in the skeletal muscle microcirculation during a HD session have been recorded by De Blasi et $\mathrm{al}^{4}$ using a NIRS device (NIMO-4 tissue probe; Nirox Srl, Brescia, Italy). They evaluated changes in the microcirculation in 20 ESRD patients (half of whom were diabetic) on HD before and every hour during a 4-hour HD session. In their study, the NIRS probe was applied to the gastrocnemius muscle and VOT was performed on the ipsilateral thigh and ankle. They demonstrated improvement of oxygen consumption rate in their diabetic patients but not in their nondiabetic population, as we did in our study. Differences in methodology, ie, use of a different NIRS technique and application of a probe to other muscle groups, contributed to the dissimilar outcomes. Our results are in agreement that $\mathrm{StO}_{2}$ remained unchanged after the HD procedure.

Another important finding of our study is the association between serum calcium and parathyroid hormone levels and the pre-dialysis $\mathrm{StO}_{2}$ during $\mathrm{HD}$, which reflects the localized equilibrium of oxygen delivery and utilization. Serum calcium is tightly regulated by parathyroid hormone, and dysregulation of this balance contributes to the development of secondary hyperparathyroidism, which in turn causes bone disease and vascular calcification in patients with ESRD, and eventually increases mortality and morbidity ${ }^{26}$ Changes in the microcirculation may promote extension of the consequences of calcification in patients with ESRD and adversely affect many organs. This result is in agreement with the observation by Sigrist et al, ${ }^{27}$ who have already highlighted the relationship between dysfunction in the microcirculation of the skin and vascular calcification in patients on HD. These authors also suggest that common pathological factors could take part in both vascular calcification and microcirculatory dysfunction, resulting in progression of the cardiovascular disease associated with ESRD.

Ultimately, in our study, patients with ESRD showed deterioration of the microcirculation at the level of the endothelium when compared with healthy subjects. Patients with ESRD are permanently exposed to uremic toxins which are poorly removed by HD and induce endothelium-dependent vasodilatation, elevated soluble biomarkers of endothelial dysfunction, and increased oxidative stress. ${ }^{19,28,29}$ Traditional risk factors, such as age and hypertension, have been associated with changes in endothelial function, ${ }^{30,31}$ and therefore might be responsible for modification of vascular elasticity. Further, hypertensive patients on HD may have more severe vascular damage, because in parallel with progression of endothelial impairment, these patients show a decrease in total vascular dilatative capacity. ${ }^{5}$ Exercise training could be an effective option for improvement of mitochondrial oxidative capacity in patients on HD. ${ }^{32}$

The limitations of this study include its small and heterogeneous patient population, and the lack of additional paired measurements that could have be recorded during more HD sessions. Further, the proportions in the sample did not help to minimize the confounding effects of age, sex, and diabetes history. Recording of $\mathrm{pH}$ changes during the HD session would potentially have further clarified the changes in microcirculation.

Overall, in this NIRS study, we documented acute improvement of baseline thenar cell metabolism over a 4-hour HD session, which correlated with single-pool Kt/V of a single treatment, and a positive relationship between pre-dialysis serum calcium and parathyroid hormone levels and changes in tissue oxygenation at steady state. These preliminary findings need to be tested using a larger data set. 
While useful markers often fail to provide direct evidence of dialysis adequacy, combination with evaluation of the microcirculation may provide additional information for the handling of patients on HD and novel targets for treatment. Interestingly, patients on HD showed impaired endothelial integrity when compared with healthy subjects.

\section{Disclosure}

The authors report no conflicts of interest in this work.

\section{References}

1. Kalender N, Tosun N. Determination of the relationship between adequacy of dialysis and quality of life and self-care agency. $J$ Clin Nurs. 2014;23:820-828.

2. Mazairac AH, de Wit GA, Penne EL, et al. Changes in quality of life over time - Dutch haemodialysis patients and general population compared. Nephrol Dial Transplant. 2011;26:1984-1989.

3. Beckert S, Sundermann K, Wolf S, Konigsrainer A, Coerper S. Haemodialysis is associated with changes in cutaneous microcirculation in diabetes mellitus. Diabet Med. 2009;26:89-92.

4. De Blasi RA, Luciani R, Punzo G, et al. Microcirculatory changes and skeletal muscle oxygenation measured at rest by non-infrared spectroscopy in patients with and without diabetes undergoing haemodialysis. Crit Care. 2009;13 Suppl 5:S9.

5. Farkas K, Nemcsik J, Kolossvary E, et al. Impairment of skin microvascular reactivity in hypertension and uraemia. Nephrol Dial Transplant. 2005;20:1821-1827.

6. Nanas S, Gerovasili V, Renieris P, et al. Non-invasive assessment of the microcirculation in critically ill patients. Anaesth Intensive Care. 2009;37:733-739.

7. Nanas S, Gerovasili V, Dimopoulos S, et al. Inotropic agents improve the peripheral microcirculation of patients with end-stage chronic heart failure. J Card Fail. 2008;14:400-406.

8. Creteur J, Carollo T, Soldati G, Buchele G, De Backer D, Vincent JL. The prognostic value of muscle $\mathrm{StO}_{2}$ in septic patients. Intensive Care Med. 2007;33:1549-1556.

9. Pareznik R, Knezevic R, Voga G, Podbregar M. Changes in muscle tissue oxygenation during stagnant ischemia in septic patients. Intensive Care Med. 2006;32:87-92.

10. Manetos C, Dimopoulos S, Tzanis G, et al. Skeletal muscle microcirculatory abnormalities are associated with exercise intolerance, ventilatory inefficiency, and impaired autonomic control in heart failure. $J$ Heart Lung Transplant. 2011;30:1403-1408.

11. Bezemer R, Lima A, Myers D, et al. Assessment of tissue oxygen saturation during a vascular occlusion test using near-infrared spectroscopy: the role of probe spacing and measurement site studied in healthy volunteers. Crit Care. 2009;13 Suppl 5:S4.

12. Lima A, Bakker J. Noninvasive monitoring of peripheral perfusion. Intensive Care Med. 2005;31:1316-1326.

13. Siafaka A, Angelopoulos E, Kritikos K, et al. Acute effects of smoking on skeletal muscle microcirculation monitored by near-infrared spectroscopy. Chest. 2007;131:1479-1485.
14. Amabile N, Guerin AP, Leroyer A, et al. Circulating endothelial microparticles are associated with vascular dysfunction in patients with end-stage renal failure. J Am Soc Nephrol. 2005;16:3381-3388.

15. Kong $\mathrm{CH}$, Farrington K. Harnessing the microcirculation to increase dialysis efficiency. Nephron. 2002;92:951.

16. Mistrik E, Dusilova-Sulkova S, Blaha V, Sobotka L. Plasma albumin levels correlate with decreased microcirculation and the development of skin defects in hemodialyzed patients. Nutrition. 2010;26:880-885.

17. Bemelmans RH, Boerma EC, Barendregt J, Ince C, Rommes JH, Spronk PE. Changes in the volume status of haemodialysis patients are reflected in sublingual microvascular perfusion. Nephrol Dial Transplant. 2009;24:3487-3492.

18. Kemp GJ, Crowe AV, Anijeet HK, et al. Abnormal mitochondrial function and muscle wasting, but normal contractile efficiency, in haemodialysed patients studied non-invasively in vivo. Nephrol Dial Transplant. 2004;19:1520-1527.

19. Tow FK, Ooi QL, Wong TY, et al. Microvascular dilatation after haemodialysis is determined by the volume of fluid removed and fall in mean arterial pressure. Kidney Blood Press Res. 2012;35:644-648.

20. Barak M, Nakhoul F, Katz Y. Pathophysiology and clinical implications of microbubbles during hemodialysis. Semin Dial. 2008;21:232-238.

21. Lichtman MA, Murphy MS, Byer BJ, Freeman RB. Hemoglobin affinity for oxygen in chronic renal disease: the effect of hemodialysis. Blood. 1974;43:417-424.

22. Mistrik E, Dusilova Sulkova S, Blaha V, et al. Evaluation of skin microcirculation during hemodialysis. Ren Fail. 2010;32:21-26.

23. Santesson P, Danielsson A, Iseda I, Adamson U, Lins PE, Jorneskog G. Impaired peripheral micro- and macrocirculation during hemodialysis in uremic patients. Int Angiol. 2010;29:362-370.

24. Weiss T, Windthorst C, Weiss C, Kreuzer J, Bommer J, Kubler W. Acute effects of haemodialysis on cutaneous microcirculation in patients with peripheral arterial occlusive disease. Nephrol Dial Transplant. 1998;13:2317-2321.

25. Hinchliffe RJ, Kirk B, Bhattacharjee D, Roe S, Jeffcoate W, Game F. The effect of haemodialysis on transcutaneous oxygen tension in patients with diabetes - a pilot study. Nephrol Dial Transplant. 2006;21:1981-1983.

26. Fukagawa M, Komaba H, Kakuta T. Hyperparathyroidism in chronic kidney disease patients: an update on current pharmacotherapy. Expert Opin Pharmacother. 2013;14:863-871.

27. Sigrist MK, McIntyre CW. Vascular calcification is associated with impaired microcirculatory function in chronic haemodialysis patients. Nephron Clin Pract. 2008;108:c121-c126.

28. Jourde-Chiche N, Dou L, Cerini C, Dignat-George F, Brunet P. Vascular incompetence in dialysis patients - protein-bound uremic toxins and endothelial dysfunction. Semin Dial. 2011;24:327-337.

29. Vlahu CA, Lemkes BA, Struijk DG, Koopman MG, Krediet RT, Vink H. Damage of the endothelial glycocalyx in dialysis patients. J Am Soc Nephrol. 2012;23:1900-1908.

30. Bonetti PO, Lerman LO, Lerman A. Endothelial dysfunction: a marker of atherosclerotic risk. Arterioscler Thromb Vasc Biol. 2003;23:168-175.

31. Preston RA, Jy W, Jimenez JJ, et al. Effects of severe hypertension on endothelial and platelet microparticles. Hypertension. 2003;41: 211-217.

32. Ryan TE, Southern WM, Brizendine JT, McCully KK. Activityinduced changes in skeletal muscle metabolism measured with optical spectroscopy. Med Sci Sports Exerc. 2013;45:2346-2352.

\section{Publish your work in this journal}

The International Journal of Nephrology and Renovascular Disease is an international, peer-reviewed open-access journal focusing on the pathophysiology of the kidney and vascular supply. Epidemiology, screening, diagnosis, and treatment interventions are covered as well as basic science, biochemical and immunological studies. The journal welcomes original research, clinical studies, reviews \& evaluations, expert opinion and commentary, case reports and extended reports. The manuscript management system is completely online and includes a very quick and fair peerreview system, which is all easy to use. Visit http://www.dovepress.com/ testimonials.php to read real quotes from published authors. 